\title{
Article \\ Numerical Modeling of Heat and Mass Transfer during Cryopreservation Using Interval Analysis
}

\author{
Anna Skorupa *(D) and Alicja Piasecka-Belkhayat (D) \\ Department of Computational Mechanics and Engineering, Silesian University of Technology, Konarskiego 18A, \\ 44-100 Gliwice, Poland; alicja.piasecka-belkhayat@polsl.pl \\ * Correspondence: anna.skorupa@polsl.pl
}

Citation: Skorupa, A.;

Piasecka-Belkhayat, A. Numerical

Modeling of Heat and Mass Transfer during Cryopreservation Using Interval Analysis. Appl. Sci. 2021, 11, 302. https://doi.org/10.3390/ app11010302

Received: 9 November 2020 Accepted: 25 December 2020 Published: 30 December 2020

Publisher's Note: MDPI stays neutral with regard to jurisdictional clai$\mathrm{ms}$ in published maps and institutional affiliations.

Copyright: (C) 2020 by the authors. Licensee MDPI, Basel, Switzerland. This article is an open access article distributed under the terms and conditions of the Creative Commons Attribution (CC BY) license (https:// creativecommons.org/licenses/by/ $4.0 /)$.

\begin{abstract}
In the paper, the numerical analysis of heat and mass transfer proceeding in an axially symmetrical articular cartilage sample subjected to the cryopreservation process is presented. In particular, a two-dimensional (axially symmetrical) model with imprecisely defined parameters is considered. The base of the heat transfer model is given by the interval Fourier equation and supplemented by initial boundary conditions. The phenomenon of cryoprotectant transport $\left(\mathrm{Me}_{2} \mathrm{SO}\right)$ through the extracellular matrix is described by the interval mass transfer equation. The liquidustracking (LT) method is used to control the temperature, which avoids the formation of ice regardless of the cooling and warming rates. In the LT process, the temperature decreases/increases gradually during addition/removal of the cryoprotectant, and the articular cartilage remains on or above the liquidus line so that no ice forms, independent of the cooling/warming rate. The discussed problem is solved using the interval finite difference method with the rules of directed interval arithmetic. Examples of numerical computations are presented in the final part of the paper. The obtained results of the numerical simulation are compared with the experimental results, realized for deterministically defined parameters.
\end{abstract}

Keywords: cryopreservation; heat and mass transfer; interval finite difference method; directed interval arithmetic

\section{Introduction}

Cryopreservation is a process which aims to preserve tissues or cells at low temperatures (between -80 and $-196^{\circ} \mathrm{C}$ ). In this process, the biological activity of tissues is reduced or completely stopped and then the physiological temperature is restored again. Successful cryopreservation does not significantly impact the basic functions of cryopreserved biological tissues or cells, for example, mechanical properties [1,2].

Cryopreservation of cells or tissues has many medical applications, such as cryobanking human cells or organ transplantation. It allows the transport of organs between different medical centers on time. The long-term storage of stem cells, for example, is the initial step toward tissue engineering, which will enable the treatment of incurable diseases and the regeneration of soft tissues [3]. Cryopreservation of articular cartilage can be helpful in its complicated treatment, considering the damage to the articular cartilage, which can lead to osteoarthritis [4-10].

Thermophysical phenomena occurring in cells or tissues during temperature decrease are regulated by chemical adjuvants, e.g., cryoprotective agents (CPA) or antifreeze proteins [1,2]. Examples of CPA are glycerol, DMSO, trehalose, and propylene glycol [3]. In cryopreservation, the process of loading/unloading of cryoprotectants (CPA) is often time-consuming and can cause osmotic damage to cells or biological tissues [11]. This is why it is important to complete this step properly. A few methods of CPA transport have been developed, such as droplet-based methods [12] and channel-based methods [2]. Recently, membrane microfluids have been proposed, which have great potential to solve 
problems with the cryoprotectant loading/unloading process [1,13-17]. Zhou et al. [11] presented a new approach to achieve safe and efficient loading/unloading of cryoprotectants, namely microfiltration-based sequential perfusion (MSP).

Generally, cryopreservation involves the following steps: (1) CPA loading, (2) freezing, (3) thawing, and (4) CPA unloading. However, there are two methods of cryopreservation: slow freezing and vitrification. The main differences between these two techniques are the cooling rate used and the CPA concentration. Slow-freezing protocols with a cooling rate of about $1{ }^{\circ} \mathrm{C} / \mathrm{min}$ use a low concentration of CPA (approx. 1-2 M), so the tissues are not exposed to damage caused by the osmotic shock of cells and the chemical toxicity of cryoprotectants. This can be the reason for ice crystals forming, which causes dehydration and tissue destruction. In contrast, vitrification (cooling rate of about $100{ }^{\circ} \mathrm{C} / \mathrm{min}$ ) is the process during which the transition from the aqueous phase to a glass state occurs without the ice crystals' formation. In the case of vitrification, the problems are toxicity and osmotic shock associated with a high CPA concentration (approx. 4-8 M) [2,3].

An alternative to the techniques is the liquidus-tracking (LT) method. It was invented by Farrant in 1962 [18] and developed by Elford et al. in 1972 [19]. The basic idea of this technique is to control the temperature as well as the concentration of CPA in the cell/tissue so that the temperature/concentration condition of the sample is on the liquidus (melting point) line or above it. This approach prevents ice crystals formation and the occurrence of a high concentration of cryoprotectants [20]. Recently, the LT method has been applied to the cryopreservation of articular cartilage by Pegg et al. [21] and Wang et al. [22]. The use of the standard methods of cryopreserving articular cartilage is problematic because of the ice crystallisation problem in chondrocytes [20].

Lately, mathematical models describing phenomena that occur during the cryopreservation process have been developed. The models present a multi-physical field's weak coupling problem, including the modelling of processes such as heat transfer, crystallization, moving-boundary problem, mass transport at the macroscale, and mass transfer across the cell membrane (with cell dehydration) [2]. Numerical modeling is an opportunity for the further development of cryopreservation. Models representing cryopreservation by slow freezing [23] and vitrification [12,24,25] have been created. Different biological tissues and cells such as stem cells $[23,26,27]$ and articular cartilage $[25,28-31]$ have been analyzed.

During the cryopreservation for heat transport modelling, the Fourier equation is used $[12,23,24,28,29]$. The heat transfer in cryopreserving organisms or during a cryosurgery can be also described by the following models: the Pennes parabolic equation (1948) [32-35], the Cattaneo-Vernotte hyperbolic model (1958) [36-39], and the dual-phase lag model [40-42]. The heat proceeding during cryopreservation should be supplemented by parameters related to the phase-change phenomena [33-35,38,39,41-43].

The mathematical model of the cryopreservation process should also consider the phenomenon of crystallization and the moving-boundary problem. Crystallization is associated with the nucleation of ice crystals and their growth in intracellular and extracellular areas. This happens when the liquid's temperature approaches the crystallization temperature $[2,12,23,24]$. The problem of the moving boundary during the cryopreservation process is related to the selection of a numerical method for calculating the moving boundary between solid and liquid phases $[2,43,44]$.

The mass transport modeling during cryopreservation is divided into: (1) macroscale flow and (2) cell-level transfer. To model the mass transfer phenomenon on a macroscale, Fick's second law is used, which determines the local concentration over time caused by diffusion $[12,25,28-31,45]$. Sometimes, Fick's second law is complemented by a velocity vector, which is defined by, e.g., the Navier-Stokes equation [11,17,34,46].

All cells have membranes that separate the extracellular environment from the intracellular solution. Hence, in the cryopreservation process model, the mass transfer across the cell membrane, which contains the simultaneous transport of water and permeable solutes, should also be included. It can be described by the following models: the Jacobs and Steward model (1932) [47,48], two-parameter (2-P) formalism [11,13,14,29,45,47-50], 
the Kedem and Katchalsky model (1958) [13,27,48,50-52], and the Mazur model (1963) [53] or its later-modified model by Levin et al. (1973) [10,54-56].

Heat and mass transfer problems are usually solved by assuming that the equations appearing in the mathematical model and all parameters in those equations are deterministic. Such assumption does not produce an exact image of the thermal and mass processes met in the cryopreservation process. It seems more reasonable to consider uncertainties related, for example, to the material parameters. Such analysis is particularly important in biomechanics because thermophysical parameters can change in a wide range (thermal conductivity, volumetric specific heat). This stems from the parameters depending on numerous individual traits such as age, sex, occupation, etc. [57,58].

In the present paper, a numerical analysis of the cryopreservation process, including heat and mass transfer proceeding, is presented. In the model, the LT method protocol for a cryopreserved articular cartilage sample was simulated. Furthermore, some thermophysical parameters cannot be determined deterministically; therefore, the values were approximated experimentally. This often causes the parameters to be inaccurate. Because of that, the interval arithmetic is used to properly interpret uncertain thermophysical parameters $[57,58]$. In this research, the thermal proceeding was modeled using the interval Fourier equation, whereas the cryoprotectant transport through the extracellular matrix was described by the interval mass transfer equation.

\section{Methods}

\subsection{Interval Governing Equations}

Thermal processes proceeding in the axially symmetrical, heterogeneous articular cartilage sample can be described by the following interval energy equation:

$$
\bar{c} \frac{\partial \bar{T}(r, z, t)}{\partial t}=\left[\frac{1}{r} \frac{\partial}{\partial r}\left(\bar{\lambda} r \frac{\partial \bar{T}(r, z, t)}{\partial r}\right)+\frac{\partial}{\partial z}\left(\bar{\lambda} \frac{\partial \bar{T}(r, z, t)}{\partial z}\right)\right]
$$

where $\bar{\lambda}=\left[\lambda^{-}, \lambda^{+}\right]$is the interval thermal conductivity, $\bar{c}=\left[c^{-}, c^{+}\right]$is the interval volumetric specific heat, $\bar{T}(r, z, t)$ is the interval temperature, $t$ is the time, $r$ and $z$ denote the cylindrical coordinates.

Equation (1) is based on the Fourier equation:

$$
c \dot{T}(X, t)=\nabla(\lambda \nabla T(X, t))
$$

where $X$ refers to the coordinate system.

The considered Equation (1) is supplemented by the boundary conditions of the 2nd or 3rd type (see Figure 1):

$$
\begin{cases}r=0,0 \leq z \leq \frac{H}{2}: & \bar{\lambda} \frac{\partial \bar{T}(r, z, t)}{\partial r}=\overline{0} \\ 0 \leq r \leq R, z=\frac{H}{2}: & -\bar{\lambda} \frac{\partial \bar{T}(r, z, t)}{\partial z}=\overline{0} \\ r=R, 0 \leq z \leq \frac{H}{2}: & -\bar{\lambda} \frac{\partial \bar{T}(r, z, t)}{\partial r}=\alpha\left(\bar{T}-T_{\text {bulk }}\right) \\ 0 \leq r \leq R, z=0: & \bar{\lambda} \frac{\partial \bar{T}(r, z, t)}{\partial z}=\alpha\left(\bar{T}-T_{\text {bulk }}\right)\end{cases}
$$

and the initial condition defined as:

$$
t=0: \quad \bar{T}(r, z, 0)=T_{0}
$$

where $T_{\text {bulk }}$ is the temperature of the bathing solution $[57,58]$. 


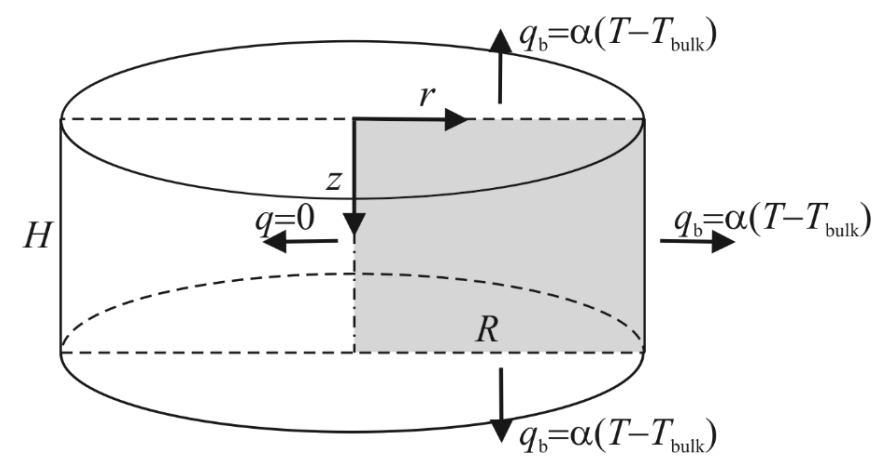

Figure 1. Domain considered and boundary conditions.

The modeling of the cryoprotectant transport through the extracellular matrix could be written as follows:

$$
\frac{\partial \bar{C}_{d}(r, z, t)}{\partial t}=\left[\frac{1}{r} \frac{\partial}{\partial r}\left(\bar{D}_{d} r \frac{\partial \bar{C}_{d}(r, z, t)}{\partial r}\right)+\frac{\partial}{\partial z}\left(\bar{D}_{d} \frac{\partial \bar{C}_{d}(r, z, t)}{\partial z}\right)\right]
$$

where $\bar{C}_{d}(r, z, t)$ is the interval cryoprotectant concentration in the extracellular matrix, while $\bar{D}_{d}$ is the interval diffusion coefficient of the cryoprotectant in the extracellular matrix estimated by the Einstein-Stokes equation [46]:

$$
\bar{D}_{d}=\frac{k_{B} \bar{T}}{6 \pi \eta r_{s}}
$$

where $k_{B}$ is the Boltzmann constant, $r_{s}$ is the radius of the spherical particle molecule, $\eta$ is the dynamic viscosity.

Equation (5) is based on Fick's second law:

$$
\dot{C}_{d}(X, t)=\nabla\left(D_{d} \nabla C_{d}(X, t)\right)
$$

The mathematical model (Equation (5)) should be supplemented by the boundary conditions (see Figure 1):

$$
\begin{cases}r=0,0 \leq z \leq \frac{H}{2}: & \frac{\partial \bar{C}_{d}(r, z, t)}{\partial r}=\overline{0} \\ 0 \leq r \leq R, z=\frac{H}{2}: & -\frac{\partial \bar{C}_{d}(r, z, t)}{\partial z}=\overline{0} \\ r=R, 0 \leq z \leq \frac{H}{2}: & \bar{C}_{d}(r, z)=0.9 C_{\text {bulk }} \\ 0 \leq r \leq R, z=0: & \bar{C}_{d}(r, z, t)=0.9 C_{\text {bulk }}\end{cases}
$$

and the initial condition in the form:

$$
t=0: \quad \bar{C}(r, z, 0)=C_{0}
$$

where $C_{\text {bulk }}$ is the cryoprotectant concentration in the bathing solution [28].

The mathematical model does not consider the phase change phenomenon. This is due to the LT method being used to model heat and mass transfer. The LT protocol regulates the temperature and concentration so that the temperature of the sample is above or on the liquidus line, which eliminates the probability of ice crystallization in cells; see the calculated eutectic temperatures and the melting points of tissues in [21].

\subsection{Numerical Model}

The numerical model of thermal and mass processes proceeding in the domain of the articular cartilage sample is based on the finite difference method (FDM) in the version presented in $[59,60]$. In this paper, the model is extended to the case of interval parameters. 
At first, the time grid was introduced with a constant step $\Delta t$ :

$$
t^{0}<t^{1}<\ldots<t^{f-2}<t^{f-1}<t^{f}<\ldots<t^{F}<\infty
$$

The sample domain was covered by a regular geometrical mesh and the five-point stars created by the central node $(i, j)$ and the adjoining ones (Figure 2). The boundary nodes were located at $0.5 h$ or $0.5 k$ with respect to the real boundary $(h, k$ are the steps of the regular mesh in directions $r$ and $z$, respectively). This approach provides a better approximation of the Neumann and Robin boundary conditions [59,60].

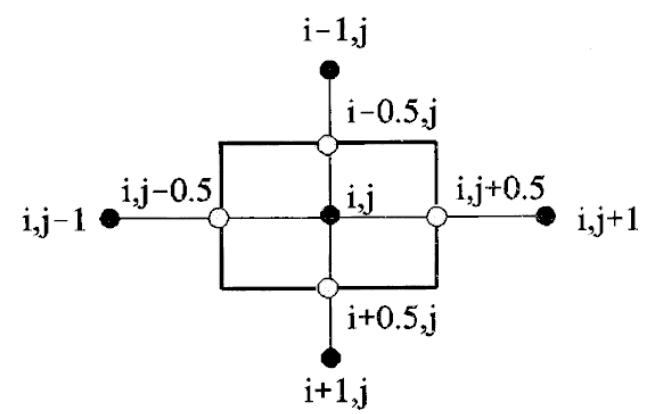

Figure 2. Five-point star.

The approximation of differential operators of the interval heat transfer Equation (1) using the mean quotient was applied:

$$
\begin{aligned}
& \left(r \bar{\lambda} \frac{\partial \bar{T}}{\partial r}\right)_{i, j+0.5}^{f-1}=r_{i, j+0.5} \bar{\lambda}_{i, j+0.5}^{f-1} \frac{\bar{T}_{i, j+1}^{f-1}-\bar{T}_{i, j}^{f-1}}{h}=\left(r_{i, j}+\frac{h}{2}\right) \frac{\bar{T}_{i, j+1}^{f-1}-\bar{T}_{i, j}^{f-1}}{\bar{R}_{i, j+1}^{f-1}} \\
& \left(r \bar{\lambda} \frac{\partial \bar{T}}{\partial r}\right)_{i, j-0.5}^{f-1}=r_{i, j-0.5} \bar{\lambda}_{i, j-0.5}^{f-1} \frac{\bar{T}_{i, j}^{f-1}-\bar{T}_{i, j-1}^{f-1}}{h}=\left(r_{i, j}-\frac{h}{2}\right) \frac{\bar{T}_{i, j}^{f-1}-\bar{T}_{i, j-1}^{f-1}}{\bar{R}_{i, j-1}^{f-1}}
\end{aligned}
$$

where the interval thermal conductivities were assumed in the form of harmonic means of values corresponding to the basic nodes:

$$
\bar{\lambda}_{i, j+0.5}^{f-1}=\frac{2 \bar{\lambda}_{i, j}^{f-1} \bar{\lambda}_{i, j+1}^{f-1}}{\bar{\lambda}_{i, j}^{f-1}+\bar{\lambda}_{i, j+1}^{f-1}}, \quad \bar{\lambda}_{i, j-0.5}^{f-1}=\frac{2 \bar{\lambda}_{i, j}^{f-1} \bar{\lambda}_{i, j-1}^{f-1}}{\bar{\lambda}_{i, j}^{f-1}+\bar{\lambda}_{i, j-1}^{f-1}}
$$

and the thermal resistances between the central node and the adjoining ones (the rules concerning the mathematical operations defined for interval numbers should be considered, of course) were the following:

$$
\bar{R}_{i, j+1}^{f-1}=\frac{0.5 h}{\bar{\lambda}_{i, j}^{f-1}}+\frac{0.5 h}{\bar{\lambda}_{i, j+1}^{f-1}}, \quad \bar{R}_{i, j-1}^{f-1}=\frac{0.5 h}{\bar{\lambda}_{i, j}^{f-1}}+\frac{0.5 h}{\bar{\lambda}_{i, j-1}^{f-1}}
$$

Using the mean differential quotient once again, the following formula was obtained:

$$
\left[\frac{1}{r} \frac{\partial}{\partial r}\left(r \bar{\lambda} \frac{\partial \bar{T}}{\partial r}\right)\right]_{i, j}^{f-1}=\frac{1}{r_{i, j} h}\left[\left(r_{i, j}+\frac{h}{2}\right) \frac{\bar{T}_{i, j+1}^{f-1}-\bar{T}_{i, j}^{f-1}}{\bar{R}_{i, j+1}^{f-1}}+\left(r_{i, j}-\frac{h}{2}\right) \frac{\bar{T}_{i, j-1}^{f-1}-\bar{T}_{i, j}^{f-1}}{\bar{R}_{i, j-1}^{f-1}}\right]
$$

where $r_{i, j}$ is the radial coordinate of the node $(i, j)$. (1):

The same approach was used for the second term on the right-hand side of Equation

$$
\left(\bar{\lambda} \frac{\partial \bar{T}}{\partial z}\right)_{i+0.5, j}^{f-1}=\bar{\lambda}_{i+0.5, j}^{f-1} \frac{\bar{T}_{i+1, j}^{f-1}-\bar{T}_{i, j}^{f-1}}{k}=\frac{\bar{T}_{i+1, j}^{f-1}-\bar{T}_{i, j}^{f-1}}{\bar{R}_{i+1, j}^{f-1}}
$$




$$
\left(\bar{\lambda} \frac{\partial \bar{T}}{\partial z}\right)_{i-0.5, j}^{f-1}=\bar{\lambda}_{i-0.5, j}^{f-1} \frac{\bar{T}_{i, j}^{f-1}-\bar{T}_{i-1, j}^{f-1}}{k}=\frac{\bar{T}_{i, j}^{f-1}-\bar{T}_{i-1, j}^{f-1}}{\bar{R}_{i-1, j}^{f-1}}
$$

and after appropriate transformations, the following formula was obtained:

$$
\left[\frac{\partial}{\partial z}\left(\bar{\lambda} \frac{\partial \bar{T}}{\partial z}\right)\right]_{i, j}^{f-1}=\frac{1}{k}\left[\frac{\bar{T}_{i+1, j}^{f-1}-\bar{T}_{i, j}^{f-1}}{\bar{R}_{i+1, j}^{f-1}}+\frac{\bar{T}_{i-1, j}^{f-1}-\bar{T}_{i, j}^{f-1}}{\bar{R}_{i-1, j}^{f-1}}\right]
$$

where:

$$
\bar{R}_{i+1, j}^{f-1}=\frac{0.5 k}{\bar{\lambda}_{i, j}^{f-1}}+\frac{0.5 k}{\bar{\lambda}_{i+1, j}^{f-1}}, \quad \quad \bar{R}_{i-1, j}^{f-1}=\frac{0.5 k}{\bar{\lambda}_{i, j}^{f-1}}+\frac{0.5 k}{\bar{\lambda}_{i-1, j}^{f-1}}
$$

The approximate form of the interval energy Equation (1) for the internal nodes $(i, j)$ and the transition $t^{f-1} \rightarrow t^{f}$ was the following:

$$
\begin{gathered}
\bar{c}_{i, j}^{f-1} \frac{\bar{T}_{i, j}^{f}-\bar{T}_{i, j}^{f-1}}{\Delta t}=\frac{\Phi_{i, j-1}}{\bar{R}_{i, j-1}^{f-1}}\left(\bar{T}_{i, j-1}^{f-1}-\bar{T}_{i, j}^{f-1}\right)+\frac{\Phi_{i, j+1}}{\bar{R}_{i, j+1}^{f-1}}\left(\bar{T}_{i, j+1}^{f-1}-\bar{T}_{i, j}^{f-1}\right)+ \\
\frac{\Phi_{i-1, j}}{\bar{R}_{i-1, j}^{f-1}}\left(\bar{T}_{i-1, j}^{f-1}-\bar{T}_{i, j}^{f-1}\right)+\frac{\Phi_{i+1, j}}{\bar{R}_{i+1, j}^{f-1}}\left(\bar{T}_{i+1, j}^{f-1}-\bar{T}_{i, j}^{f-1}\right)
\end{gathered}
$$

where:

$$
\Phi_{i, j-1}=\frac{r_{i, j}-0.5 h}{r_{i, j} h}, \quad \Phi_{i, j+1}=\frac{r_{i, j}+0.5 h}{r_{i, j} h}, \quad \Phi_{i-1, j}=\Phi_{i+1, j}=\frac{1}{k}
$$

are the shape functions of the differential mesh. As visible, the explicit scheme of the interval FDM was applied here.

In a similar way, the derivatives appearing in the interval mass Equation (5) were approximated. Thus:

$$
\begin{aligned}
& \left(r \bar{D}_{d} \frac{\partial \overline{\mathcal{C}}_{d}}{\partial r}\right)_{i, j+0.5}^{f-1}=r_{i, j+0.5}\left(\bar{D}_{d}\right)_{i, j+0.5}^{f-1} \frac{\left(\overline{\mathcal{C}}_{d}\right)_{i, j+1}^{f-1}-\left(\overline{\mathcal{C}}_{d}\right)_{i, j}^{f-1}}{h}=\left(r_{i, j}+\frac{h}{2}\right) \frac{\left(\overline{\mathcal{C}}_{d}\right)_{i, j+1}^{f-1}-\left(\overline{\mathcal{C}}_{d}\right)_{i, j}^{f-1}}{\bar{W}_{i, j+1}^{f-1}} \\
& \left(r \bar{D}_{d} \frac{\partial \bar{C}_{d}}{\partial r}\right)_{i, j-0.5}^{f-1}=r_{i, j-0.5}\left(\bar{D}_{d}\right)_{i, j-0.5}^{f-1} \frac{\left(\overline{\mathcal{C}}_{d}\right)_{i, j}^{f-1}-\left(\overline{\mathcal{C}}_{d}\right)_{i, j-1}^{f-1}}{h}=\left(r_{i, j}-\frac{h}{2}\right) \frac{\left(\overline{\mathcal{C}}_{d}\right)_{i, j}^{f-1}-\left(\overline{\mathcal{C}}_{d}\right)_{i, j-1}^{f-1}}{\overline{\mathrm{W}}_{i, j-1}^{f-1}}
\end{aligned}
$$

where the interval diffusion coefficients were assumed in the form of harmonic means of values corresponding to the basic nodes:

$$
\left(\bar{D}_{d}\right)_{i, j+0.5}^{f-1}=\frac{2\left(\bar{D}_{d}\right)_{i, j}^{f-1}\left(\bar{D}_{d}\right)_{i, j+1}^{f-1}}{\left(\bar{D}_{d}\right)_{i, j}^{f-1}+\left(\bar{D}_{d}\right)_{i, j+1}^{f-1}}, \quad\left(\bar{D}_{d}\right)_{i, j-0.5}^{f-1}=\frac{2\left(\bar{D}_{d}\right)_{i, j}^{f-1}\left(\bar{D}_{d}\right)_{i, j-1}^{f-1}}{\left(\bar{D}_{d}\right)_{i, j}^{f-1}+\left(\bar{D}_{d}\right)_{i, j-1}^{f-1}}
$$

and the diffusion resistances between the central node and the adjoining ones were the following:

$$
\bar{W}_{i, j+1}^{f-1}=\frac{0.5 h}{\left(\bar{D}_{d}\right)_{i, j}^{f-1}}+\frac{0.5 h}{\left(\bar{D}_{d}\right)_{i, j+1}^{f-1}}, \quad \quad \bar{W}_{i, j-1}^{f-1}=\frac{0.5 h}{\left(\bar{D}_{d}\right)_{i, j}^{f-1}}+\frac{0.5 h}{\left(\bar{D}_{d}\right)_{i, j-1}^{f-1}}
$$

Using the mean differential quotient again, the following formula was obtained:

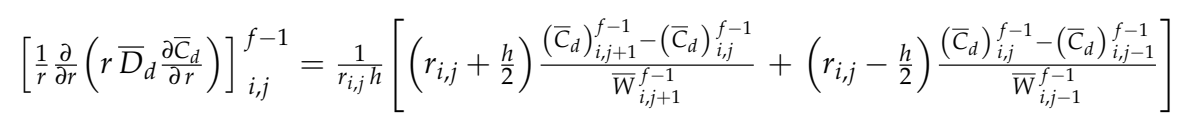

The same approach was used for the second term on the right-hand side of Equation (5), and after transformations, we obtained:

$$
\left[\frac{\partial}{\partial z}\left(\bar{D}_{d} \frac{\partial \bar{C}_{d}}{\partial z}\right)\right]_{i, j}^{f-1}=\frac{1}{k}\left[\frac{\left(\bar{C}_{d}\right)_{i+1, j}^{f-1}-\left(\bar{C}_{d}\right)_{i, j}^{f-1}}{\bar{W}_{i+1, j}^{f-1}}+\frac{\left(\bar{C}_{d}\right)_{i-1, j}^{f-1}-\left(\bar{C}_{d}\right)_{i, j}^{f-1}}{\bar{W}_{i-1, j}^{f-1}}\right]
$$


while:

$$
\bar{W}_{i+1, j}^{f-1}=\frac{0.5 k}{\left(\bar{D}_{d}\right)_{i, j}^{f-1}}+\frac{0.5 k}{\left(\bar{D}_{d}\right)_{i+1, j}^{f-1}}, \quad \bar{W}_{i-1, j}^{f-1}=\frac{0.5 k}{\left(\bar{D}_{d}\right)_{i, j}^{f-1}}+\frac{0.5 k}{\left(\bar{D}_{d}\right)_{i-1, j}^{f-1}}
$$

The final approximate form of the interval mass Equation (5) for the internal nodes ( $i$, $j)$ and the transition $t^{f-1} \rightarrow t^{f}$ was the following:

$$
\begin{gathered}
\frac{\left(\bar{C}_{d}\right)_{i, j}^{f}-\left(\bar{C}_{d}\right)_{i, j}^{f-1}}{\Delta t}=\frac{\Phi_{i, j-1}}{\bar{W}_{i, j-1}^{f-1}}\left[\left(\bar{C}_{d}\right)_{i, j-1}^{f-1}-\left(\bar{C}_{d}\right)_{i, j}^{f-1}\right]+\frac{\Phi_{i, j+1}}{\bar{W}_{i, j+1}^{f-1}}\left[\left(\bar{C}_{d}\right)_{i, j+1}^{f-1}-\left(\bar{C}_{d}\right)_{i, j}^{f-1}\right] \\
+\frac{\Phi_{i-1, j}}{\bar{W}_{i-1, j}^{f-1}}\left[\left(\bar{C}_{d}\right)_{i-1, j}^{f-1}-\left(\bar{C}_{d}\right)_{i, j}^{f-1}\right]+\frac{\Phi_{i+1, j}}{\bar{W}_{i+1, j}^{f-1}}\left[\left(\bar{C}_{d}\right)_{i+1, j}^{f-1}-\left(\bar{C}_{d}\right)_{i, j}^{f-1}\right]
\end{gathered}
$$

To summarize, for each transition $t^{f-1} \rightarrow t^{f}, f=1,2, \ldots, F$, based on the Equation (20) the interval temperature $\bar{T}_{i, j}^{f}$ is calculated and then based on the Equation (29) the interval cryoprotectant concentration $\left(\bar{C}_{d}\right)_{i, j}^{f}$ is determined.

The method of attaching boundary conditions is discussed in detail in [60].

The system of Equations (20) and (29) was solved using the assumption of the stability condition for the explicit differential scheme [59,60].

All mathematical operations leading to the determination of the temperature field and the concentration field corresponding to time level $t^{f}$ were performed according to the rules of directed interval arithmetic (see Appendix A). For example, using Equation (29), interval subtraction and interval division were performed (see Equations (A8) and (A9)), while in Equation (20), an interval multiplication operation was applied additionally (see Equation (A6)).

\subsection{Example of Computations}

At the stage of numerical computations, the homogenous cylindrical articular cartilage sample of dimensions $H=1 \mathrm{~mm}$ and $R=3 \mathrm{~mm}$ has been considered. In the numerical example, thermal conductivity $\bar{\lambda}=[\lambda-0.05 \lambda, \lambda+0.05 \lambda]$ and the volumetric specific heat $\bar{c}=[c-0.05 c, c+0.05 c]$ were assumed as interval numbers, where $\lambda=0.518 \mathrm{~W} \cdot \mathrm{m}^{-1} \cdot \mathrm{K}^{-1}$ and $c=3.924 \times 10^{6} \mathrm{~J} \cdot \mathrm{m}^{-3} \cdot \mathrm{K}^{-1}$. Additionally, the following input data were introduced: initial temperature $T_{0}=22{ }^{\circ} \mathrm{C}$, the initial concentration $C_{0}=0 \%(w / w)$, heat transfer coefficient $\alpha=525 \mathrm{~W} \cdot \mathrm{m}^{-2} \cdot \mathrm{K}^{-1}$ [28]. To determine the diffusion coefficient (Equation (5)), the following parameters were used: the Boltzmann constant $k_{\mathrm{B}}=1.38 \times 10^{-23} \mathrm{~J} \cdot \mathrm{K}^{-1}$, radius of the spherical particle molecule $r_{\mathrm{s}}=2.541 \times 10^{-10} \mathrm{~m}$ and the dynamic viscosity $\eta=1.996 \times 10^{-3} \mathrm{~Pa} \cdot \mathrm{s}[28,61]$.

The experiment using the LT approach was carried as follows: The cylindrical sample of articular cartilage was immersed in a bathing solution whose temperature and concentration were regulated using computer control. The cryoprotectant was delivered to the sample in such a manner that prevented ice crystals forming without causing toxicity. This is the sample temperature being close to the liquidus temperature during the process (the melting point of the sample was changed by the cryoprotectant's impact) [21,22].

\section{Results}

In this work, we used the LT protocol reported by Pegg et al. [21]. It consisted of eight steps in the cooling phase (the temperatures in steps 1 and 2 were the same; therefore, it can be considered that the cooling phase for the temperature consisted of seven steps) and seven steps in the heating phase. In each step, which lasted a certain amount of time, the temperature and concentration of the bathing solution were kept at the same level. For example, step 1 in the cooling phase lasted $10 \mathrm{~min}$, and the temperature as well as concentration of the bathing solution were equal to $22{ }^{\circ} \mathrm{C}$ and $10 \%(w / w)$, respectively. Similarly, in step 1 in the heating phase, the temperature and concentration of the bathing solution were equal to $-48.5{ }^{\circ} \mathrm{C}$ and $63 \%(w / w)$, respectively. Such conditions in this step were maintained for $30 \mathrm{~min}$. The temperature of the bathing solution, $T_{\text {bulk }}$, and the 
concentration of the bathing solution, $C_{\text {bulk }}$, regulated in accordance with the LT method presented in $[21,28]$ for the remaining steps are shown in Table 1 and in Figure 3.

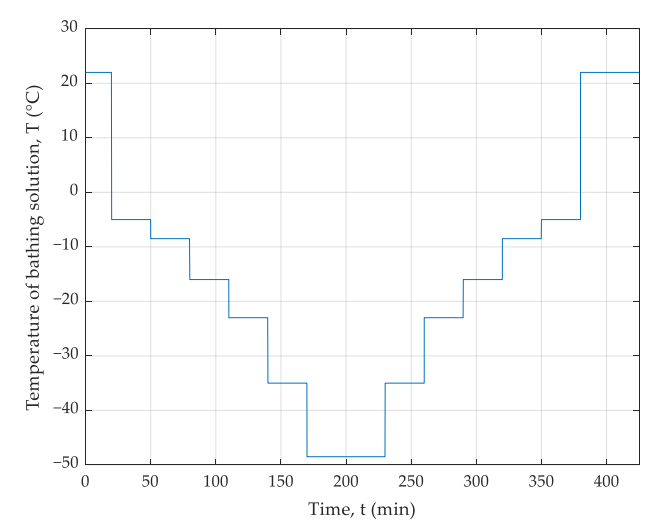

(a)

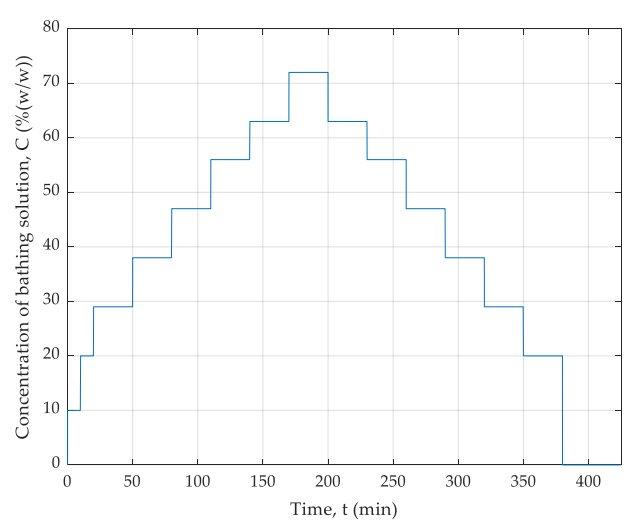

(b)

Figure 3. History of the bathing solution parameters: (a) temperature and (b) concentration.

In the mathematical model, the bathing solution parameters refer to boundary conditions. On the basis of the determined boundary conditions, it was possible to calculate the interval temperature and interval concentration in the given nodes inside the sample using the interval heat transfer equation and the interval mass transfer equation.

The computations were performed using the interval FDM, with the assumption that the time step $\Delta t=0.001 \mathrm{~s}$, mesh steps are $h=0.0001 \mathrm{~m}$, and $k=0.00005 \mathrm{~m}$.

Table 1 also presents a comparison of temperatures and the $\mathrm{Me}_{2} \mathrm{SO}$ concentrations obtained in the simulation, with the temperature set according to the stepwise LT protocol of Pegg et al. [21,28]. The obtained results refer to the point with the coordinates $r=0.1$ $\mathrm{mm}$ and $z=0.45 \mathrm{~mm}$.

Firstly, the simulation without using interval arithmetic rules for constant values of the parameters $c$ and $\lambda$ was performed. The results of these computations are provided in Figures 4 and 5.

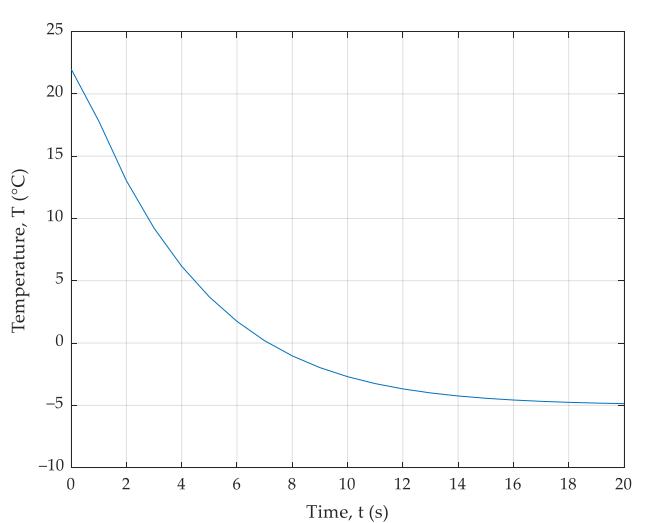

(a)

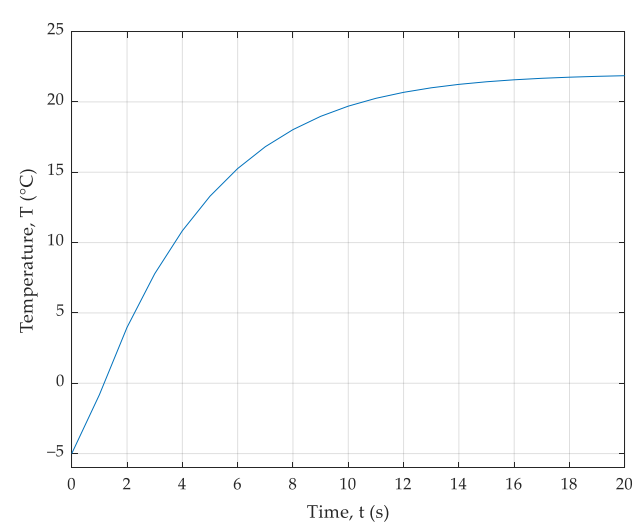

(b)

Figure 4. History of the temperature over time without using interval arithmetic: (a) from $22{ }^{\circ} \mathrm{C}$ to $-5{ }^{\circ} \mathrm{C}$ and (b) from $-5{ }^{\circ} \mathrm{C}$ to $22{ }^{\circ} \mathrm{C}$. 
Table 1. Temperatures and concentrations obtained in the simulation.

\begin{tabular}{|c|c|c|c|c|c|c|c|c|c|c|c|}
\hline \multirow[t]{2}{*}{ Phase } & \multirow[t]{2}{*}{ Step } & \multirow{2}{*}{$\begin{array}{c}\text { Time } \\
t(\min )\end{array}$} & \multirow{2}{*}{$\begin{array}{c}\begin{array}{c}\text { Temperature of } \\
\text { Bathing Solution }\end{array} \\
T_{\text {bulk }}\left({ }^{\circ} \mathrm{C}\right)\end{array}$} & \multirow{2}{*}{$\begin{array}{c}\begin{array}{l}\text { Concentration of } \\
\text { Bathing Solution }\end{array} \\
C_{\text {bulk }}(\%(w / w))\end{array}$} & \multicolumn{2}{|c|}{$\begin{array}{c}\text { Interval } \\
\text { Temperature }\end{array}$} & \multicolumn{2}{|c|}{$\begin{array}{c}\text { Interval } \\
\text { Concentration }\end{array}$} & \multirow{2}{*}{$\begin{array}{c}\text { Pegg et al.'s } \\
\text { Experimental } \\
\text { Data [21] }\end{array}$} & \multirow{2}{*}{$\begin{array}{c}\begin{array}{c}\text { Relative } \\
\text { Error }\end{array} \\
\delta \\
(\%)\end{array}$} & \multirow{2}{*}{$\begin{array}{c}\begin{array}{c}\text { Yu et al.'s } \\
\text { Simulation } \\
\text { Data [28] }\end{array} \\
C_{\mathrm{d}}(\%(w / w))\end{array}$} \\
\hline & & & & & $\begin{array}{l}T^{-} \\
\left({ }^{\circ} \mathrm{C}\right)\end{array}$ & $\begin{array}{c}T^{+} \\
\left({ }^{\circ} \mathrm{C}\right)\end{array}$ & $\begin{array}{c}C_{\mathrm{d}^{-}} \\
(\%(w / w))\end{array}$ & $\begin{array}{c}C_{\mathrm{d}^{+}}^{+} \\
(\%(w / w))\end{array}$ & & & \\
\hline \multirow{8}{*}{ Cooling } & 1 & 10 & 22 & 10 & 22 & 22 & 7.83 & 7.83 & - & - & 6.79 \\
\hline & 2 & 10 & 22 & 20 & 22 & 22 & 16.72 & 16.72 & $16.3 \pm 1.3$ & 2.58 & 15.82 \\
\hline & 3 & 30 & -5 & 29 & -5.51 & -4.54 & 26.08 & 26.06 & $24.5 \pm 1.1$ & 6.41 & 25.16 \\
\hline & 4 & 30 & -8.5 & 38 & -9.37 & -7.71 & 34.18 & 34.13 & $34.2 \pm 0.9$ & 0.88 & 32.99 \\
\hline & 5 & 30 & -16 & 47 & -17.63 & -14.51 & 42.27 & 42.15 & $41.7 \pm 3.3$ & 1.22 & 39.81 \\
\hline & 6 & 30 & -23 & 56 & -25.36 & -20.86 & 50.37 & 50.15 & $47.8 \pm 2.8$ & 5.15 & 45.80 \\
\hline & 7 & 30 & -35 & 63 & -38.58 & -31.75 & 56.67 & 56.27 & $52.2 \pm 1.3$ & 8.18 & 49.22 \\
\hline & 8 & 30 & -48.5 & 72 & -53.47 & -43.99 & 64.74 & 64.07 & $55.9 \pm 2.9$ & 15.21 & 50.67 \\
\hline \multirow{6}{*}{ Heating } & 1 & 30 & -48.5 & 63 & -53.47 & -43.99 & 56.76 & 56.17 & - & - & 52.43 \\
\hline & 2 & 30 & -35 & 56 & -38.58 & -31.75 & 50.43 & 50.08 & - & - & 52.86 \\
\hline & 3 & 30 & -23 & 47 & -25.36 & -20.86 & 42.33 & 42.14 & - & - & 46.78 \\
\hline & 4 & 30 & -16 & 38 & -17.64 & -14.51 & 34.24 & 34.12 & - & - & 37.54 \\
\hline & 5 & 30 & -8.5 & 29 & -9.37 & -7.71 & 6.12 & 6.08 & - & - & 27.68 \\
\hline & 7 & 45 & 22 & 0 & 22 & 22 & $0.59 \times 10^{-3}$ & $0.59 \times 10^{-3}$ & - & - & 0.02 \\
\hline
\end{tabular}




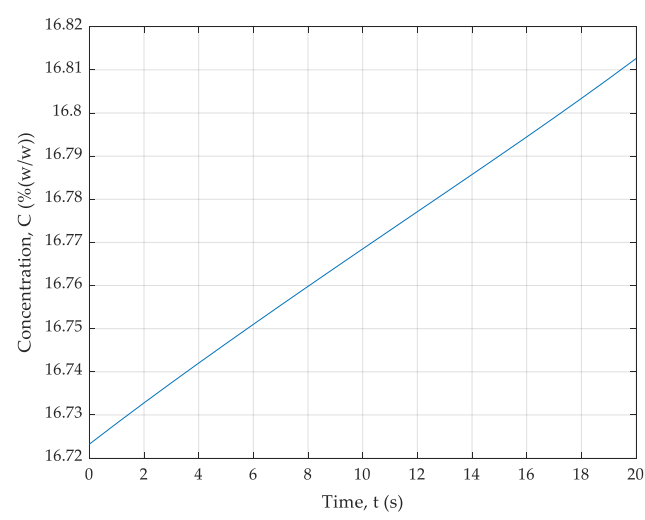

(a)

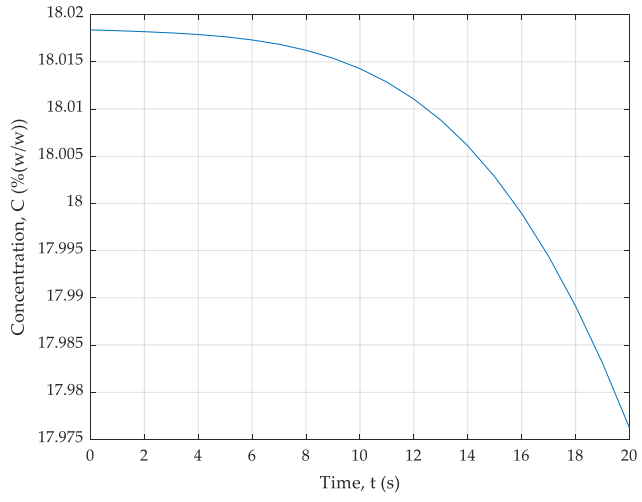

(b)

Figure 5. History of the concentration over time without using interval arithmetic: (a) from $22{ }^{\circ} \mathrm{C}$ to $-5{ }^{\circ} \mathrm{C}$ and (b) from $-5^{\circ} \mathrm{C}$ to $22{ }^{\circ} \mathrm{C}$.

Figure 4 presents the history of the temperature over time for transition from 22 to $-5{ }^{\circ} \mathrm{C}$ from step 2 to step 3 in the cooling phase (Figure $4 \mathrm{a}$ ) and transition from -5 to $22^{\circ} \mathrm{C}$ from step 6 to step 7 in the heating phase (Figure $4 \mathrm{~b}$ ). The diagram shows that the required temperature is reached within $20 \mathrm{~s}$.

Figure 5 shows the history of the concentration over time for transition from 22 to $-5{ }^{\circ} \mathrm{C}$ from step 2 to step 3 in the cooling phase (Figure $5 \mathrm{a}$ ) and transition from -5 to $22{ }^{\circ} \mathrm{C}$ from step 6 to step 7 in the heating phase (Figure $5 b$ ).

Afterward, calculations for a model using interval arithmetic rules were performed. Figure 6 illustrates the distribution of temperatures $T^{-}$(Figure 6a) and $T^{+}$(Figure 6b) as well as the concentrations $C_{d}-\left(\right.$ Figure $6 \mathrm{c}$ ) and $C_{d}+$ (Figure $6 \mathrm{~d}$ ) for step 3 after $10 \mathrm{~s}$ in the cooling phase.

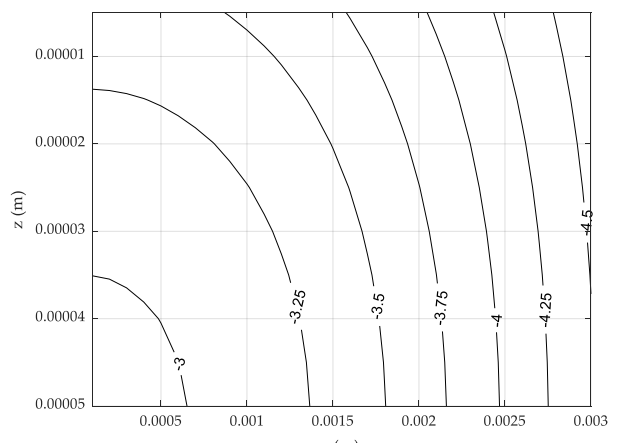

(a)

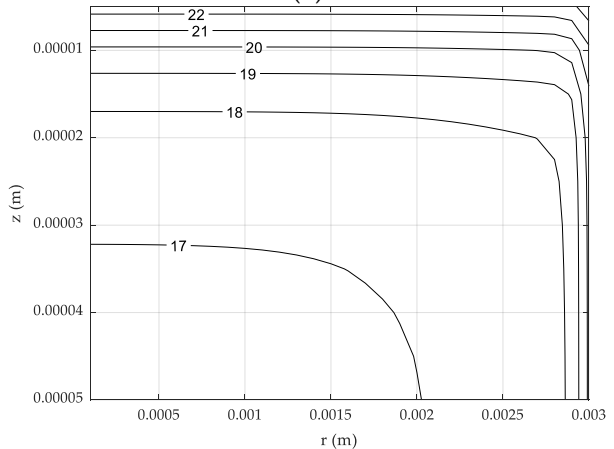

(c)

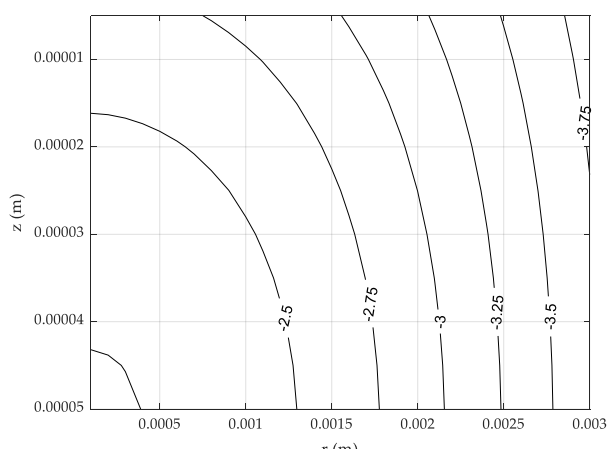

(b)

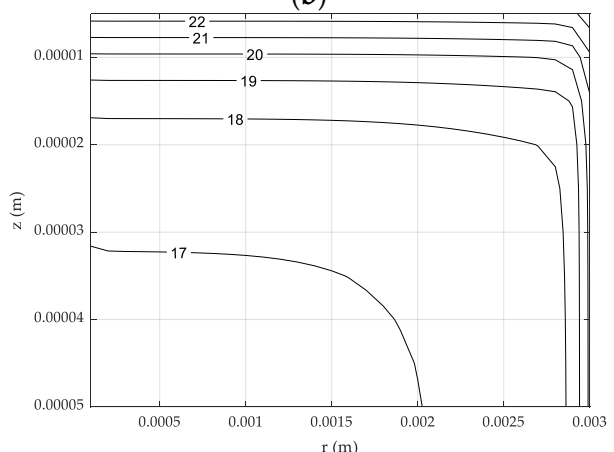

(d)

Figure 6. Distribution of the temperature and the concentration for step 3 after $10 \mathrm{~s}$ in the cooling phase: $(\mathbf{a}) \mathrm{T}^{-},(\mathbf{b}) \mathrm{T}^{+}$, (c) $\mathrm{Cd}^{-}$, and (d) $\mathrm{Cd}^{+}$. 
Figure 7 shows the cooling curves for the given point at the moment of transition from 22 to $-5{ }^{\circ} \mathrm{C}$ from step 2 to step 3 in the cooling phase (Figure 7a) and the heating curves at the moment of transition from -5 to $22{ }^{\circ} \mathrm{C}$ from step 6 to step 7 in the heating phase (Figure $7 b$ ).

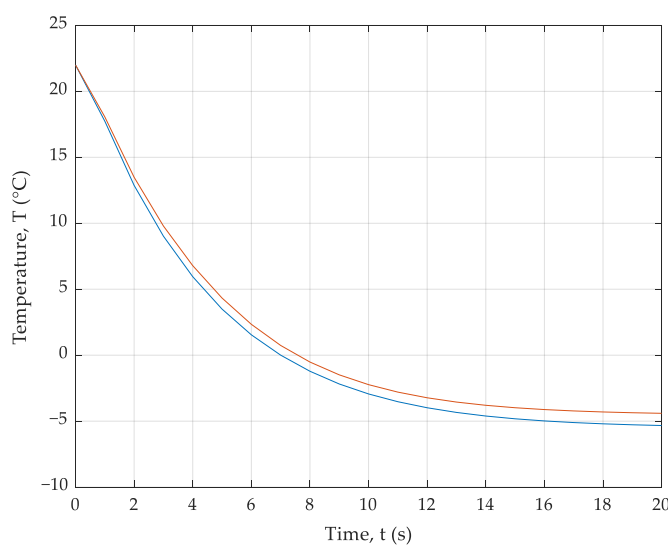

(a)

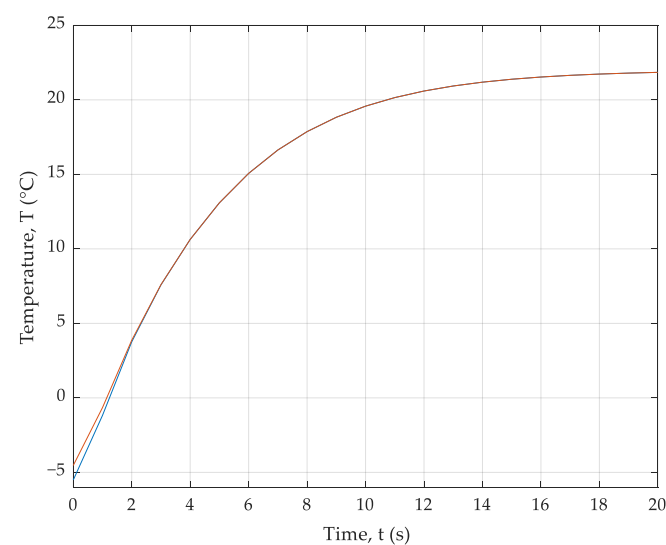

(b)

Figure 7. History of the temperature over time: (a) from 22 to $-5{ }^{\circ} \mathrm{C}$ and (b) from $-5{ }^{\circ} \mathrm{C}$ to $22^{\circ} \mathrm{C}$.

The numerical simulation achieved very narrow temperature intervals. Additionally, the temperature value obtained from the experiment was within the calculated temperature interval (Table 1).

The obtained concentration intervals increased over time in the case of cooling, while during heating, they narrowed again, which can be seen by analyzing the history of the concentration over time presented in Figure 8. Comparing the obtained concentration intervals with the results of experimental studies carried out by Pegg et al. [21], one can see that the values determined by means of numerical simulation did not coincide with the results measured by the experimental method (Table 1). In turn, the concentration values presented in [28] are more similar to the experimental results determined by Pegg et al. On this basis, we concluded that the resulting simulation error was caused by using the Einstein-Stokes model to estimate the diffusion coefficient (compared with the diffusion coefficient in [28]).

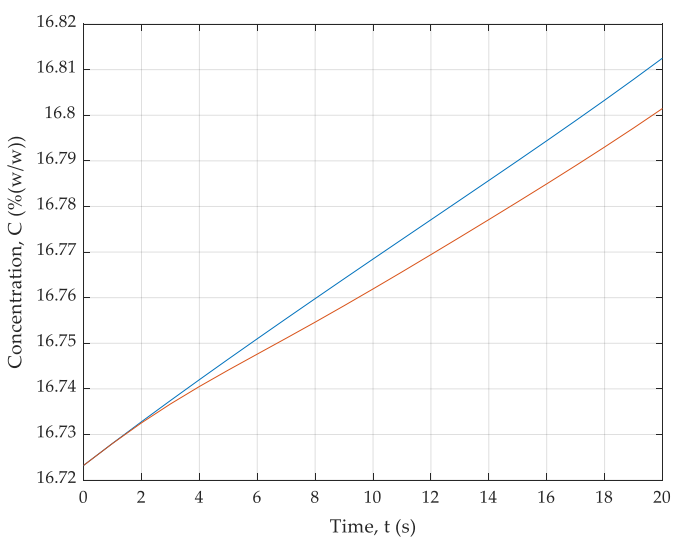

(a)

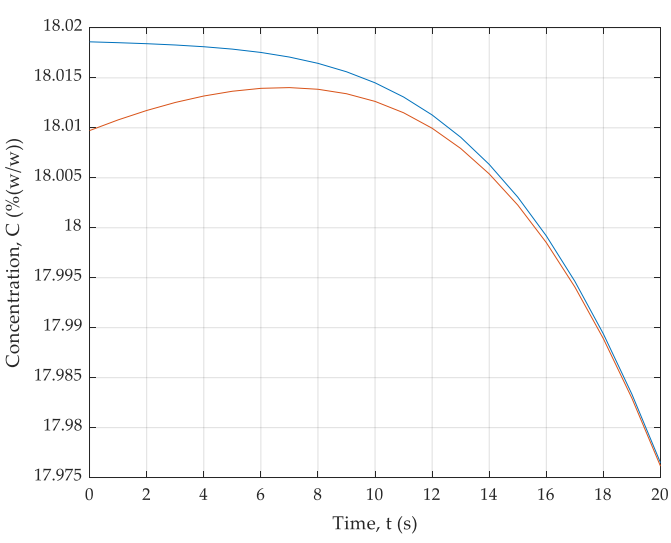

(b)

Figure 8. History of the concentration over time: (a) from 22 to $-5{ }^{\circ} \mathrm{C}$ and (b) from -5 to $22{ }^{\circ} \mathrm{C}$. 


\section{Discussion}

In this paper, the numerical analysis of heat and mass transfer proceeding in an axially symmetrical articular cartilage sample subjected to the cryopreservation process was presented. The problem discussed was solved using the interval FDM with the rules of directed interval arithmetic. The mathematical model is based on Fourier and mass diffusion interval equations, assuming interval values of thermophysical parameters.

This approach allows the mathematical model to include imprecise values that are closer to reality, as these parameters are determined by experimental means. The use of interval values allows obtaining solutions in the form of intervals, which better reflect the analyzed process. The obtained interval temperatures and concentrations were compared with the results of the experiment and [21]. While satisfactory results were obtained for temperatures, different results were obtained for concentrations than in the experiment, probably because of estimation of the diffusion coefficient by the Einstein-Stokes model differently than in [28].

\section{Conclusions}

In this paper, numerical analysis of the cryopreservation process, including heat and mass transfer proceeding, was considered. The interval version of the FDM allows finding a numerical solution in interval form, and such information may be important especially for parameters that are difficult to estimate, for example, tissue parameters.

The obtained results of the numerical simulation were compared with the results of the experiment realized for deterministically defined parameters, such as thermal conductivity and volumetric specific heat. Considering imprecise parameter values in the mathematical model allows obtaining temperatures and cryoprotectant concentrations in the form of intervals, which, in turn, allows modeling the cryopreservation phenomenon closer to reality.

Numerical modeling of the cryopreservation process is an opportunity for further development in medicine as it allows a better understanding of the physicochemical phenomena occurring in tissues and cells.

The next stage of the work will be to extend the presented mass transfer model with the phenomenon of cryoprotectant transport $\left(\mathrm{Me}_{2} \mathrm{SO}\right)$ across the cell membrane.

Author Contributions: Conceptualization, A.P.-B. and A.S.; methodology, A.P.-B. and A.S.; software, A.S.; validation, A.P.-B. and A.S.; formal analysis, A.P.-B.; investigation, A.P.-B. and A.S.; resources, A.P.-B.; data curation, A.S.; writing-original draft preparation, A.P.-B. and A.S.; writing-review and editing, A.P.-B.; visualization, A.S.; supervision, A.P.-B.; project administration, A.P.-B.; funding acquisition, A.S. All authors have read and agreed to the published version of the manuscript.

Funding: The research was partially funded from financial resources from the statutory subsidy of the Faculty of Mechanical Engineering, Silesian University of Technology, in 2020.

Institutional Review Board Statement: Not applicable.

Informed Consent Statement: Not applicable.

Data Availability Statement: Not applicable.

Acknowledgments: The research was partially funded from financial resources from the statutory subsidy of the Faculty of Mechanical Engineering, Silesian University of Technology, in 2020.

Conflicts of Interest: The authors declare no conflict of interest.

\section{Appendix A Directed Interval Arithmetic}

Let us consider a directed interval $\bar{a}$, which can be defined as a set $\mathbf{D}$ of all directed pairs of real numbers defined as $\bar{a}=\left[a^{-}, a^{+}\right]:=\left\{\bar{a} \in \mathbf{D} \mid a^{-}, a^{+} \in \mathbf{R}\right\}$, where $a^{-}$and $a^{+}$ denote the beginning and the end of the interval, respectively $[62,63]$. 
The left or the right endpoint of interval $\bar{a}$ can be denoted as $a^{s}, s \in\{+,-\}$, where $s$ is a binary variable. This variable can be expressed as a product of two binary variables and is defined as:

$$
\begin{aligned}
& ++=--=+ \\
& +-=-+=-
\end{aligned}
$$

An interval is called proper if $a^{-}<a^{+}$, improper if $a^{-}>a^{+}$and degenerate if $a^{-}=a^{+}$. The set of all directed interval numbers can be described as $\mathbf{D}=\mathbf{P} \cup \mathbf{I}$, where $\mathbf{P}$ denotes a set of all directed proper intervals and $\mathbf{I}$ denotes a set of all improper intervals.

Additionally a subset $\mathbf{Z}=\mathbf{Z}_{\mathbf{P}} \cup \mathbf{Z}_{\mathbf{I}} \in \mathbf{D}$ should be defined, where $\mathbf{Z}_{\mathbf{P}}=\left\{\bar{a} \in \mathbf{P} \mid a^{-} \leq 0 \leq a^{+}\right\}$and $\mathbf{Z}_{\mathbf{I}}=\left\{\bar{a} \in \mathbf{I} \mid a^{+} \leq 0 \leq a^{-}\right\}$.

For directed interval numbers, two binary variables are defined. The first of them is the direction variable:

$$
\tau(\bar{a})= \begin{cases}+, & \text { if } a^{-} \leq a^{+} \\ -, & \text {if } a^{-}>a^{+}\end{cases}
$$

and the other one is the sign variable:

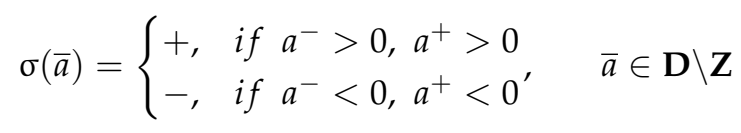

In the set of directed interval numbers, the basic mathematical operations for $\bar{a}=$ $\left[a^{-}, a^{+}\right]$and $\bar{b}=\left[b^{-}, b^{+}\right]$belonging to $\mathbf{D}$ can be defined as follows:

$$
\begin{aligned}
& \bar{a}+\bar{b}=\left[a^{-}+b^{-}, a^{+}+b^{+}\right] \\
& \bar{a}-\bar{b}=\left[a^{-}-b^{+}, a^{+}-b^{-}\right] \\
& \bar{a} \cdot \bar{b}= \begin{cases}{\left[a^{-\sigma(\bar{b})} \cdot b^{-\sigma(\bar{a})}, a^{\sigma(\bar{b})} \cdot b^{\sigma(\bar{a})}\right]} & \bar{a}, \bar{b} \in \mathbf{D} \backslash \mathbf{Z} \\
{\left[a^{\sigma(\bar{a}) \tau(\bar{b})} \cdot b^{-\sigma(\bar{a})}, a^{\sigma(\bar{a}) \tau(\bar{b})} \cdot b^{\sigma(\bar{a})}\right],} & \bar{a} \in \mathbf{D} \backslash \mathbf{Z}, \bar{b} \in \mathbf{Z} \\
{\left[a^{-\sigma(\bar{b})} \cdot b^{\sigma(\bar{b}) \tau(\bar{a})}, a^{\sigma(\bar{b})} \cdot b^{\sigma(\bar{b}) \tau(\bar{a})}\right],} & \bar{a} \in \mathbf{Z}, \bar{b} \in \mathbf{D} \backslash \mathbf{Z} \\
{\left[\min \left(a^{-} \cdot b^{+}, a^{+} \cdot b^{-}\right), \max \left(a^{-} \cdot b^{-}, a^{+} \cdot b^{+}\right)\right], \quad \bar{a}, \bar{b} \in \mathbf{Z}_{\mathbf{P}}} \\
{\left[\max \left(a^{-} \cdot b^{-}, a^{+} \cdot b^{+}\right), \min \left(a^{-} \cdot b^{+}, a^{+} \cdot b^{-}\right)\right], \quad \bar{a}, \bar{b} \in \mathbf{Z}_{\mathbf{I}}} \\
0, \quad\left(\bar{a} \in \mathbf{Z}_{\mathbf{P}}, \bar{b} \in \mathbf{Z}_{\mathbf{I}}\right) \cup\left(\bar{a} \in \mathbf{Z}_{\mathbf{I}}, \bar{b} \in \mathbf{Z}_{\mathbf{P}}\right)\end{cases}
\end{aligned}
$$

and

$$
\bar{a} / \bar{b}=\left\{\begin{array}{lc}
{\left[a^{-\sigma(\bar{b})} / b^{\sigma(\bar{a})}, a^{\sigma(\bar{b})} / b^{-\sigma(\bar{a})}\right],} & \bar{a}, \bar{b} \in \mathbf{D} \backslash \mathbf{Z} \\
{\left[a^{-\sigma(\bar{b})} / b^{-\sigma(\bar{b}) \tau(\bar{a})}, a^{\sigma(\bar{b})} / b^{-\sigma(\bar{b}) \tau(\bar{a})}\right],} & \bar{a} \in \mathbf{Z}, \bar{b} \in \mathbf{D} \backslash \mathbf{Z}
\end{array}\right.
$$

In the directed interval arithmetic, two extra operators are defined: inversion of summation $-\mathbf{D}^{\bar{a}}=\left[-a^{-},-a^{+}\right]$and inversion of multiplication $1 / \mathbf{D}^{\bar{a}}=\left[1 / a^{-}, 1 / a^{+}\right]$This way, two additional mathematical operations can be defined as follows:

$$
\bar{a}-\mathbf{D} \bar{b}=\left[a^{-}-b^{-}, a^{+}-b^{+}\right]
$$

and

$$
\bar{a} / \mathbf{D}^{\bar{b}}=\left\{\begin{array}{l}
{\left[a^{-\sigma(\bar{b})} / b^{-\sigma(\bar{a})}, a^{\sigma(\bar{b})} / b^{\sigma(\bar{a})}\right], \quad \bar{a}, \bar{b} \in \mathbf{D} \backslash \mathbf{Z}} \\
{\left[a^{-\sigma(\bar{b})} / b^{\sigma(\bar{b})}, a^{\sigma(\bar{b})} / b^{\sigma(\bar{b})}\right], \bar{a} \in \mathbf{Z}, \bar{b} \in \mathbf{D} \backslash \mathbf{Z}}
\end{array}\right.
$$

which now makes it possible to obtain the number $\overline{0}$ by subtracting two of the same intervals and the number $\overline{1}$ by dividing the interval by itself, which is impossible using classic interval arithmetic [62,63]. 


\section{References}

1. Zhao, G.; Fu, J. Microfluidics for cryopreservation. Biotechnol. Adv. 2017, 35, 323-336. [CrossRef] [PubMed]

2. Xu, F.; Moon, S.; Zhang, X.; Shao, L.; Song, Y.S.; Demirci, U. Multi-scale heat and mass transfer modelling of cell and tissue cryopreservation. Philos. Trans. R. Soc. A Math. Phys. Eng. Sci. 2010, 368, 561-583. [CrossRef] [PubMed]

3. Jang, T.H.; Park, S.C.; Yang, J.H.; Kim, J.Y.; Seok, J.H.; Park, U.S.; Choi, C.W.; Lee, S.R.; Han, J. Cryopreservation and its clinical applications. Integr. Med. Res. 2017, 6, 12-18. [CrossRef] [PubMed]

4. Peters, A.E.; Comerford, E.J.; Macaulay, S.; Bates, K.T.; Akhtar, R. Micromechanical properties of canine femoral articular cartilage following multiple freeze-thaw cycles. J. Mech. Behav. Biomed. Mater. 2017, 71, 114-121. [CrossRef]

5. Abazari, A.; Jomha, N.M.; Elliott, J.A.W.; McGann, L.E. Cryopreservation of articular cartilage. Cryobiology 2013, 66, 201-209. [CrossRef]

6. Onari, I.; Hayashi, M.; Ozaki, N.; Tsuchiya, H. Vitreous preservation of articular cartilage from cryoinjury in rabbits. Cryobiology 2012, 65, 98-103. [CrossRef]

7. Cetinkaya, G.; Arat, S. Cryopreservation of cartilage cell and tissue for biobanking. Cryobiology 2011, 63, 292-297. [CrossRef]

8. Brockbank, K.G.M.; Chen, Z.Z.; Song, Y.C. Vitrification of porcine articular cartilage. Cryobiology 2010, 60, 217-221. [CrossRef]

9. Laouar, L.; Fishbein, K.; McGann, L.E.; Horton, W.E.; Spencer, R.G.; Jomha, N.M. Cryopreservation of porcine articular cartilage: MRI and biochemical results after different freezing protocols. Cryobiology 2007, 54, 36-43. [CrossRef]

10. Wu, W.T.; Lyu, S.-R.; Hsieh, W.H. Cryopreservation and biophysical properties of articular cartilage chondrocytes. Cryobiology 2005, 51, 330-338. [CrossRef]

11. Zhou, X.; Jiang, Z.; Liang, X.M.; Liu, J.; Fang, P.; Liu, Z.; Gao, D. Microfiltration-based sequential perfusion: A new approach for improved loading/unloading of cryoprotectants. Sens. Actuators B Chem. 2020, 312, 127957. [CrossRef]

12. Shi, M.; Feng, S.; Zhang, X.; Ji, C.; Xu, F.; Lu, T.J. Droplet based vitrification for cell aggregates: Numerical analysis. J. Mech. Behav. Biomed. Mater. 2018, 82, 383-393. [CrossRef] [PubMed]

13. Zhou, X.; Liang, X.M.; Wang, J.; Du, P.; Gao, D. Theoretical and experimental study of a membrane-based microfluidics for loading and unloading of cryoprotective agents. Int. J. Heat Mass Transf. 2018, 127, 637-644. [CrossRef]

14. Zheng, Y.; Zhao, G.; Zhang, Y.; Gao, R. On-chip loading and unloading of cryoprotectants facilitate cell cryopreservation by rapid freezing. Sens. Actuators B Chem. 2018, 225, 647-656. [CrossRef]

15. Scherr, T.; Pursley, S.; Todd Monroe, W.; Nandakumar, K. A numerical study on the loading of cryoprotectant cocktails-on-a-chip. Part II: The cellular experience. Int. J. Heat Mass Transf. 2014, 78, 1292-1299. [CrossRef]

16. Scherr, T.; Pursley, S.; Todd Monroe, W.; Nandakumar, K. A numerical study on the loading of cryoprotectant cocktails-on-a-chip, Part I: Interacting miscible viscous fluids. Int. J. Heat Mass Transf. 2014, 78, 1284-1291. [CrossRef]

17. Song, Y.S.; Moon, S.; Hulli, L.; Hasan, S.K.; Kayaalp, E.; Demirci, U. Microfluidics for cryopreservation. Lab. Chip 2009, 9, $1874-1881$. [CrossRef]

18. Farrant, J. Mechanism of Cell Damage during Freezing and Thawing and its Prevention. Nature 1965, 205, 1284-1287. [CrossRef]

19. Elford, B.C.; Walter, C.A. Effects of electrolyte composition and $\mathrm{pH}$ on the structure and function of smooth muscle cooled to $-79^{\circ} \mathrm{C}$ in unfrozen media. Cryobiology 1972, 9, 82-100. [CrossRef]

20. Kay, A.G.; Hoyland, J.A.; Rooney, P.; Kearney, J.N.; Pegg, D.E. A liquidus tracking approach to the cryopreservation of human cartilage allografts. Cryobiology 2015, 71,77-84. [CrossRef]

21. Pegg, D.E.; Wang, L.; Vaughan, D. Cryopreservation of articular cartilage. Part 3: The liquidus-tracking method. Cryobiology 2006, 52, 360-368. [CrossRef] [PubMed]

22. Wang, L.; Pegg, D.E.; Lorrison, J.; Vaughan, D.; Rooney, P. Further work on the cryopreservation of articular cartilage with particular reference to the liquidus tracking (LT) method. Cryobiology 2007, 55, 138-147. [CrossRef]

23. Hayashi, Y.; Horiguchi, I.; Kino-oka, M.; Sugiyama, H. Slow freezing process design for human induced pluripotent stem cells by modeling intracontainer variation. Comput. Chem. Eng. 2020, 132, 106597. [CrossRef]

24. Zhang, Y.; Zhao, G.; Chapal Hossain, S.M.; He, X. Modeling and experimental studies of enhanced cooling by medical gauze for cell cryopreservation by vitrification. Int. J. Heat Mass Transf. 2017, 114, 1-7. [CrossRef] [PubMed]

25. Shardt, N.; Al-Abbasi, K.K.; Yu, H.; Jomha, N.M.; McGann, L.E.; Elliott, J.A.W. Cryoprotectant kinetic analysis of a human articular cartilage vitrification protocol. Cryobiology 2016, 73, 80-92. [CrossRef]

26. Casula, E.; Traversari, G.; Fadda, S.; Klymenko, O.V.; Kontoravdi, C.; Cincotti, A. Modelling the osmotic behaviour of human mesenchymal stem cells. Biochem. Eng. J. 2019, 151, 107296. [CrossRef]

27. Xu, Y.; Zhang, L.; Xu, J.; Wei, Y.; Xu, X. Membrane permeability of the human pluripotent stem cells to $\mathrm{Me}_{2} \mathrm{SO}$, glycerol and 1,2-propanediol. Arch. Biochem. Biophys. 2014, 550-551, 67-76. [CrossRef]

28. Yu, X.; Zhang, S.; Chen, G. Modeling the addition/removal of dimethyl sulfoxide into/from articular cartilage treated with the liquidus-tracking method. Int. J. Heat Mass Transf. 2019, 141, 719-730. [CrossRef]

29. Lawson, A.; Mukherjee, I.N.; Sambanis, A. Mathematical modeling of cryoprotectant addition and removal for the cryopreservation of engineered or natural tissues. Cryobiology 2012, 64, 1-11. [CrossRef]

30. Zhang, S.Z.; Yu, X.Y.; Chen, G.M. Permeation of dimethyl sulfoxide into articular cartilage at subzero temperatures. J. Zhejiang Univ. Sci. B 2012, 13, 213-220. [CrossRef]

31. Mukherjee, I.N.; Li, Y.; Song, Y.C.; Long, R.C.; Sambanis, A. Cryoprotectant transport through articular cartilage for long-term storage: Experimental and modeling studies. Osteoarthr. Cartil. 2008, 1379-1386. [CrossRef] [PubMed] 
32. Pennes, H.H. Analysis of Tissue and Arterial Blood Temperatures in the Restin Human Forearm. J. Appl. Physiol. 1948, 1, 93-122. [CrossRef] [PubMed]

33. Ge, M.Y.; Shu, C.; Yang, W.M.; Chua, K.J. Incorporating an immersed boundary method to study thermal effects of vascular systems during tissue cryo-freezing. J. Therm. Biol. 2017, 64, 92-99. [CrossRef] [PubMed]

34. Wang, Z.; Zhao, G.; Wang, T.; Yu, Q.; Su, M.; He, X. Three-dimensional numerical simulation of the effects of fractal vascular trees on tissue temperature and intracelluar ice formation during combined cancer therapy of cryosurgery and hyperthermia. Appl. Therm. Eng. 2015, 90, 296-304. [CrossRef]

35. Deng, Z.-S.; Liu, J. Numerical simulation of selective freezing of target biological tissues following injection of solutions with specific thermal properties. Cryobiology 2005, 50, 183-192. [CrossRef] [PubMed]

36. Cattaneo, C. A form of heat conduction equation which eliminates the paradox of instantaneous propagation. Comptes Rendus 1958, 247, 431-433.

37. Vernotte, M.P. Les paradoxes de la theorie continue de l'equation de la chaleur. Comptes Rendus 1958, 246, 3154-3155.

38. Singh, S.; Kumar, S. Freezing of Biological Tissues during Cryosurgery Using Hyperbolic Heat Conduction Model. Math. Model. Anal. 2015, 20, 443-456. [CrossRef]

39. Ahmadikia, H.; Moradi, A. Non-Fourier phase change heat transfer in biological tissues during solidification. Heat Mass Transf. 2012, 48, 1559-1568. [CrossRef]

40. Kumar, S.; Singh, S. Numerical Study on Biological Tissue Freezing Using Dual Phase Lag Bio-Heat Equation. In Trends in Biomathematics: Modeling, Optimization and Computational Problems; Springer: Cham, Switzerland, 2018; pp. 283-300.

41. Mochnacki, B.; Majchrzak, E. Numerical model of thermal interactions between cylindrical cryoprobe and biological tissue using the dual-phase lag equation. Int. J. Heat Mass Transf. 2017, 108, 1-10. [CrossRef]

42. Moradi, A.; Ahmadikia, H. Numerical study of the solidification process in biological tissue with blood flow and metabolism effects by the dual phase lag model. Proc. Inst. Mech. Eng. Part H J. Eng. Med. 2012, 226, 406-416. [CrossRef] [PubMed]

43. Liu, Z.; Wan, R.; Muldrew, K.; Sawchuk, S.; Rewcastle, J. A level set variational formulation for coupled phase change/mass transfer problems: Application to freezing of biological systems. Finite Elem. Anal. Des. 2004, 40, 1641-1663. [CrossRef]

44. Kundu, P.; Sukumar, S.; Kar, S.P. Numerical modeling for freezing and cryogenic preservation for viability of biological tissue. Mater. Today Proc. 2018, 5, 18823-18832. [CrossRef]

45. Benson, J.D.; Higgins, A.Z.; Desai, K.; Eroglu, A. A toxicity cost function approach to optimal CPA equilibration in tissues. Cryobiology 2018, 80, 144-155. [CrossRef]

46. Liu, W.; Zhao, G.; Shu, Z.; Wang, T.; Zhu, K.; Gao, D. High-precision approach based on microfluidic perfusion chamber for quantitative analysis of biophysical properties of cell membrane. Int. J. Heat Mass Transf. 2015, 86, 869-879. [CrossRef]

47. Jacobs, M.H.; Stewart, D.R. A simple method for the quantitative measurement of cell permeability. J. Cell. Comp. Physiol. 1932, 1, 71-82. [CrossRef]

48. Elmoazzen, H.Y.; Elliott, J.A.W.; McGann, L.E. Osmotic Transport across Cell Membranes in Nondilute Solutions: A New Nondilute Solute Transport Equation. Biophys. J. 2009, 96, 2559-2571. [CrossRef]

49. Jacobs, M.H. The simultaneous measurement of cell permeability to water and to dissolved substances. J. Cell. Comp. Physiol. 1933, 2, 427-444. [CrossRef]

50. Xu, X.; Cui, Z.; Urban, J.P. Measurement of the chondrocyte membrane permeability to $\mathrm{Me}_{2} \mathrm{SO}$, glycerol and 1,2-propanediol. Med. Eng. Phys. 2003, 25, 573-579. [CrossRef]

51. Kedem, O.; Katchalsky, A. Thermodynamic analysis of the permeability of biological membranes to non-electrolytes. Biochim. Biophys. Acta 1958, 27, 229-246. [CrossRef]

52. Xu, X.; Cui, Z.F.; Wilkins, R.J.; Urban, J.P.G. Intracellular $\mathrm{pH}$ changes in isolated bovine articular chondrocytes during the loading and removal of cryoprotective agents. Cryobiology 2003, 46, 161-173. [CrossRef]

53. Mazur, P. Kinetics of Water Loss from Cells at Subzero Temperatures and the Likelihood of Intracellular Freezing. J. Gen. Physiol. 1963, 47, 347-369. [CrossRef]

54. Levin, R.L.; Cravalho, E.G.; Huggins, C.E. A membrane model describing the effect of temperature on the water conductivity of erythrocyte membranes at subzero temperatures. Cryobiology 1976, 13, 415-429. [CrossRef]

55. Devismita, D.; Kumar, A. Effect of cryoprotectant on optimal cooling rate during cryopreservation. Cryobiology 2015, 70, 53-59. [CrossRef] [PubMed]

56. Thirumala, S.; Gimble, J.M.; Devireddy, R.V. Transport phenomena during freezing of adipose tissue derived adult stem cells. Biotechnol. Bioeng. 2005, 92, 372-383. [CrossRef] [PubMed]

57. Mochnacki, B.; Piasecka-Belkhayat, A. Numerical modeling of skin tissue heating using the interval finite difference method. MCB Mol. Cell. Biomech. 2013, 10, 233-244. [CrossRef] [PubMed]

58. Piasecka-Belkhayat, A. Interval boundary element method for $2 \mathrm{D}$ transient diffusion problem using the directed interval arithmetic. Eng. Anal. Bound. Elem. 2011, 35, 259-263. [CrossRef]

59. Majchrzak, E.; Mochnacki, B. Numerical Methods. Theoretical Base, Practical Aspects, Algorithms; Silesian University of Technology: Gliwice, Poland, 2004.

60. Mochnacki, B.; Suchy, J. Numerical Methods in Computations of Foundry Processes; PFTA: Cracow, Poland, 1995.

61. Schulze, B.M.; Watkins, D.L.; Zhang, J.; Ghiviriga, I.; Castellano, R.K. Estimating the shape and size of supramolecular assemblies by variable temperature diffusion ordered spectroscopy. Org. Biomol. Chem. Suppl. Mater. 2014, 12, S1-S27. [CrossRef] 
62. Markov, S. On directed interval arithmetic and its applications. In J. UCS The Journal of Universal Computer Science; Springer: Berlin/Heidelberg, Germany, 1996; Volume 1, pp. 514-526.

63. Neumaier, A. Interval Methods for Systems of Equations; Cambridge University Press: Cambridge, NY, USA; Melbourne, Sydney, 1990. 